\title{
APLIKASI QUALITY FUNCTION DEPLOYMENT DALAM PENINGKATAN PELAYANAN RAWAT INAP KELAS III RSUD DR. SAIFUL ANWAR MALANG
}

\author{
Sugeng Santoso ${ }^{1}$, Muthma'inah ${ }^{2}$
}

\begin{abstract}
Dr. Saiful Anwar Malang is a state hospital has done it's job and function, but in $3^{\text {rd }}$ class of paviliun room, the number of patient decrease dramatically. It's concerned with quality of this hospital. To answer this problem, research was done using Quality Function Deployment (QFD). Quality Function Deployment is a tool which design some needs include customers represented as a voice of customer and including some competitions and also groups some activities that usually called affinitas graphic ang getting a benchmarking for it's competitions.

From the result analysis can be showed that main attribute for patience is a accuracy. And from House Of Quality can be found that getting a periodic meeting to evaluate this hospital and also increase a service can be made 20 concepts.
\end{abstract}

Key Words : QFD, Customers attribute, $\mathrm{HOQ}$

\section{PENDAHULUAN}

Dewasa ini banyak Rumah Sakit yang bersaing ketat dan berusaha melakukan pengembangan-pengembangan metode dan teknologi yang lebih tinggi untuk meningkatkan kualitas pelayanan dan fasilitas yang diberikan. Dalam hal ini adalah pasien sebagai penentu utama akan kualitas jasa tersebut. Untuk itu diperlukanlah suatu langkah perbaikan untuk mengidentifikasi dan menganalisa bentuk pelayanan dan fasilitas yang bagaimanakah yang bisa menjawab permasalahanpermasalahan pasien atau keinginan konsumen. Salah satu cara untuk menjawab permasalahan tersebut adalah dilakukan analisa dengan metode aplikasi Quality Function Deployment(QFD) dimana QFD merupakan metode yang berorientasi pada keinginan konsumen atau alat analisa kebutuhan konsumen dalam merancang suatu produk/jasa dengan spesifikasi keinginan konsumen akan tetapi juga mempertimbangkan kemampuan teknis perusahaan.

Penelitian ini dilakukan di Rumah Sakit Umum Daerah Saiful Anwar Malang di mana sistem pelayanan dan fasilitas terdiri dari jenis kelas yang menunjukkan tingkatan-tingkatan mulai dari kelas VIP(Paviliyun), I,II, dan kelas III.Kelas VIP adalah kelas yang paling mahal yang ditujukkan dengan fasilitas yang diberikan juga paling bagus dibandingkan kelas yang lainnya. Sedangkan kelas yang terendah adalah kelas III, di mana fasilitas yang diberikan juga paling ekonomis.Peneliti 
memilih obyek penelitian pada ruang rawat inap kelas III setelah melakukan studi pendahuluan obyek penelitian, karena pada survei awal di tiap jenis kelas tadi dan melihat secara langsung bagaimana proses pelayanan, ternyata banyak keluhan yang timbul dari pasien rawat inap kelas III. Peneliti juga mengadakan interview secara tidak langsung yang bisa disimpulkan bahwa hal itu (keluhan) timbul bukan semata karena fasilitas yang diberikan, tetapi lebih mengarah pada struktur sistem pelayanan yang diberikan. Di samping itu pihak Rumah Sakit sendiri juga memerlukan langkah penanganan yang lebih baik guna meningkatkan pelayanannya.

\section{TINJAUAN PUSTAKA}

\section{RUMAH SAKIT}

\section{Kualitas Pelayanan Kesehatan}

Berbagai konsep tentang kualitas pelayanan kesehatan telah mengalir kepada masyarakat khususnya dalam pelayanan kesehatan di Rumah Sakit.Keterpaduan pengelolaan Rumah Sakit merupakan bagian dari manajemen umum yang mencakup 3 aspek, yaitu :

1. Sumber : administrasi, organisasi, produser, peralatan, logistik, keuangan, sistim informasi, dan sebagainya.

2. Proses : kontrol, monitoring, manajemen, meningkatkan kualitas pelayanan.

3. Hasil akhir : Kepuasan pasien, pembayaran.

\section{Ciri-ciri Rumah Sakit}

Berbeda dengan instansi yang lain, Rumah Sakit mempunyai ciri-ciri yang unik yang selanjutnya akan berpengaruh terhadap cara pengelolaannya. Ciri-ciri tersebut antara lain :

1. Padat karya, hal ini tercermin dari banyaknya tenaga kerja dengan berbagai profesi.

2. Bekerja tanpa istirahat selama masih berfungsi.

3. Pada dasarnya pelayanan yang diberikan bersifat individual.

4. Penuh ketidak pastian, karena kedatangan penderita dengan bermacam penyakit dan problemnya tidak selalu dapat diramalkan.

5. Mix input, disamping sumber daya manusia yang merupakan input paling dominan, obat dan bahan serta alat merupakan input yang sangat besar untuk keperluan sakit, yang tentunya memerlukan pengelolaan tersendiri.

6. Terdapat saling ketergantungan yang tinggi antara unit dan instansi di Rumah Sakit.

Prinsip Organisasi, Manajemen dan Tata Kerja Rumah Sakit

Organisasi secara definisi sederhana dapat dirumuskan sebagai berikut:

* Wadah bagi pengelompokan kerja sama manusia.

* Alat bagi pencapaian suatu tujuan.

Organisasi Manajemen Rumah Sakit Umum Daerah (RSUD)

Kegiatan uatama dari organisasi RSUD ini adalah kegiatan pelayanan medis 
dan pelayanan perawatan, disamping kegiatan uatama tersebut ada juga kegiatan pendukung. Sehingga dalam kegiatannya dapat dikelompokkan dalam 2 bagian :

1. Kegiatan utama (pelayanan kesehatan)

2. Kegiatan pendukung

* Kegiatan perencanaan, pengembangan dan pengawasan yang dilakukan direksi

* Kegiatan logistik dilakukan oleh bagian rumah tangga.

* Kegiatan pembinaan tenaga kerja dilakukan oleh bagian personalia

* Kegiatan pengelolaan keuangan meliputi

* Pengelolaan data dan melayani permintaan data baik untuk kebutuhan intern maupun ekstern dilakukan bagian Diklit

* Kegiatan surat-menyurat baik urusan keluar maupun di dalam dilakukan oleh bagian umum.

* Kegiatan hubungan masyarakat dilakukan oleh Direksi dengan bantuan bagian Humas (Hubungan Masyarakat).

Penyebaran Fungsi Kualitas (Quality Function Deployment)

QFD merupakan alat perencanaan yang digunakan untuk memenuhi harapanharapan customer. Pendekatan disiplin ilmu ini terletak pada disain produk, rekayasa, dan produktivitas dan memberikan evaluasi yang mendalam terhadap suatu produk. Suatu organisasi yang mengimplementasikan QFD dengan tepat, dapat meningkatkan pengetahuan rekayasa, produktivitas, dan kualitas dan mengurangi ongkos, waktu pengembangan produk serta perubahan-perubahan rekayasa.

\section{Tahap-tahap Implementasi QFD}

Terdiri dari 3 fase dengan didahului oleh fase perencanaan dan persiapan. Ketiga fase tersebut adalah :
a. tahap pengumpulan voice of customer
b. tahap penyusunan rumah kualitas
c. tahap analisa dan interpretasi

\section{Tahap Perencanaan dan Persiapan}

1. Menetapkan Dukungan yang bersifat organisasi.

2. Menentukan Tujuan-tujuan.

3. Memutuskan Siapa Pelanggan kita

4. Memutuskan Horison waktunya.

5. Memutuskan Cakupan Produk

6. Memutuskan Teamnya dan Hubungannya dengan Organisasi.

7. Membuat Jadwal Pelaksanaan QFD.

8. Melengkapi fasilitas dan materialnya.

\section{Mengumpulkan Suara Pelanggan (Voice of Customer)}

Proses QFD membutuhkan data pelanggan yang ditulis sebagai atributatribut dari produk atau service

\section{Klasifikasikan Kebutuhan-kebutuhan Pelanggan}

Model Klein menggunakan revealed importance dan stated importance tiap atribut untuk mengklasifikasi kebutuhan pelanggan menjadi empat kategori :

- Kebutuhan yang diharapkan (Expected needs) : High stated importance dan Low revealed importance. 
- Kebutuhan impact rendah (Low-impact needs) : Low stated importance dan Low revealed importance.

- Kebutuhan impact tinggi (High-impact needs) : High stated importance dan High revealed importance.
- Kebutuhan yang tersembunyi (Hidden needs) : Low stated importance, high revealed importance.

Tabel 1

Voice of Customer Table part 1

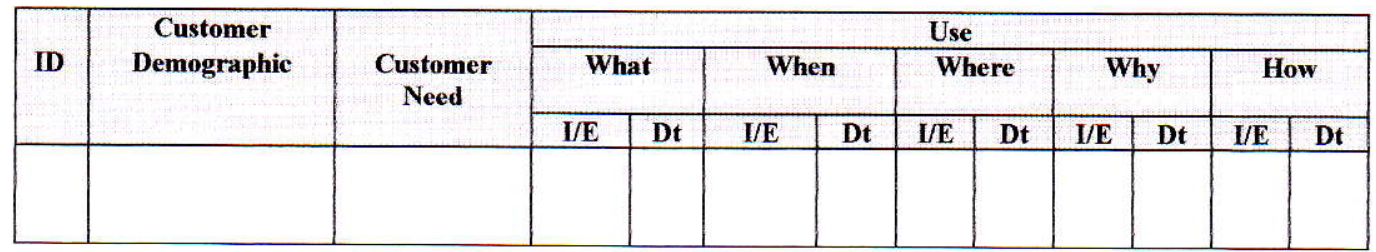

Tabel 2

Voice of Customer Table part 2

\begin{tabular}{|c|c|c|c|c|}
\hline Customer need & Function & Reliability & Target Value & SQC \\
\hline & & & & \\
\hline
\end{tabular}

\section{Raw weight}

Nilai dari Raw weight untuk tiap customer need adalah :

Raw weight $=$ (Importance to Customer $) \mathrm{x}$ (improvement ratio) $\mathrm{x}$ (sales point)

\section{Normalized Raw Weight}

Nilai dari normalized raw weight adalah sebagai berikut :

Normalized Raw Weight $=$ Raw Weight $/$

Raw Weight Total
Menyusun Rumah Kualitas (House of Quality)

TAHAP I Matriks Kebutuhan Pelanggan

TAHAP II Matriks Perencanaan

TAHAP III Respon Teknis

TAHAP IV Menentukan Hubungan Respon Teknis dengan Kebutuhan Pelanggan

TAHAP V Korelasi Teknis

TAHAP VI Rekayasa Teknis (Benchmarking ,Penetapan Target \& Priority) 


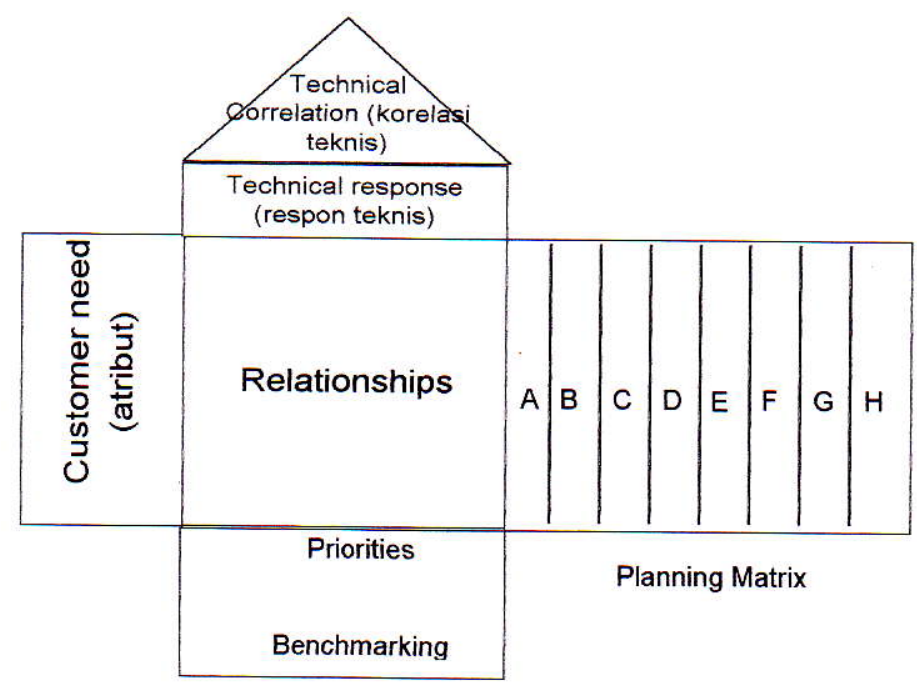

\section{Gambar 1}

Bentuk Rumah Kualitas (House of Quality)

A. Importance to Customer.

B. Customer Satisfaction Performance

C. Competitor Satisfaction Performance

D. Goal

E. Improvement Ratio

F. Sales Point

G. Raw Weight

H. Normalized Raw Weight

\section{Substitute Quality Characteristics (SQC)}

Dalam memunculkan SQC ini terdapat beberapa cara, yaitu Performance Measurement, Product Function, Product Subsystem, dan Process Step.

\section{Identifikasi sampel penelitian}

Untuk menentukan jumlah sampel penelitian dilakukan perhitungan Bernoulli seperti pada rumus berikut : $N \geq \frac{(Z \alpha / 2 /)_{p \cdot q}}{e^{2}}$

Apabila proporsi kuisioner yang dianggap benar adalah $95 \%$ dan proporsi yang dianggap salah adalah 10\% maka jumlah sampel minimum adalah :

$$
N \geq \frac{(1.96)^{2} \times 0.95 \times 0.05}{(0.05)^{2}}
$$

$N \geq 72.99 \approx 73$

\section{Uji Validitas}

Pengujian validitas ini dilakukan dengan internal validity, di mana kriteria yang dipakai berasal dari dalam alat tes itu sendiri dan masing-masing item tiap variabel dikorelasikan dengan nilai total yang diperoleh dari koefisien korelasi produk moment. Jika koefisien korelasi rendah dan tidak signifikan, maka item yang bersangkutan gugur. Taraf signifikan yang digunakan adalah $5 \%$.

$$
r=\frac{N\left(\sum x y\right)-\left(\sum x \Sigma y\right)}{\left\{\left[N \Sigma x^{2}-\left(\sum x\right)^{2}\right]\left[N \Sigma y^{2}-\left(\sum y\right)^{2}\right]\right\}^{1 / 2}}
$$

keterangan :

$\mathrm{x}=$ skor tiap-tiap variabel

$\mathrm{y}=$ skor total tiap responden

$\mathrm{N}=$ jumlah responden

\section{Uji Keandalan (Reliability)}

Suatu alat tes dikatakan mempunyai taraf kepercayaan jika tes tersebut memberikan hasil yang tepat (ajeg). Rumus 
untuk koefisien variansi (dengan $\alpha$ cronbrach) adalah :

$$
R t t=\frac{M(V t-V x)}{M-1(V t)}
$$

keterangan :

$\mathrm{V}_{\mathrm{t}}=$ variansi total

$\mathrm{V}_{\mathrm{x}}=$ variansi butir-butir

$\mathrm{M}=$ jumlah butir

apabila Rtt lebih besar dari 0,4 maka dianggap cukup baik.

\section{Planning Matrix}

Planning Matix seringkali disebut Customer Competitive Assessment dalam beberapa literatur. Data-datanya adalah sebagai berik

\section{Penentuan korelasi teknis}

Tahap ini memetakan interrelationships dan interdependencies antara SQC.

\section{Tabel 1}

Derajat Pengaruh Teknis pada Korelasi Teknis

\begin{tabular}{|c|c|}
\hline & Pengertian \\
\hline++ & Pengaruh positif sangat kuat \\
\hline+ & Pengaruh positif cukup kuat \\
\hline- & Pengaruh negatif cukup kuat \\
\hline & Pengaruh negatif sangat kuat \\
\hline
\end{tabular}

\section{Membuat matriks hubungan}

\section{(Relationship Matrix)}

Untuk tiap atribut (customer needs) akan dicari solusi atau rekayasa teknisnya dalam QFD kita mengenal 4 kemungkinan, yaitu :

1. Performansi kepuasan customer tidak ada hubungannya dengan SQC.
2. Performansi kepuasan customer mungkin ada hubungannya dengan SQC.

3. Performansi kepuasan customer sedikit ada hubungannya dengan SQC.

4. Performansi kepuasan customer sangat kuat hubungannya dengan SQC.

Tabel 2

Simbol dalam Relationship Matrix

\begin{tabular}{|c|c|c|}
\hline Simbol & $\begin{array}{c}\text { Nilai } \\
\text { numer }\end{array}$ & $\begin{array}{c}\text { pengertian / tingkat } \\
\text { hubungan }\end{array}$ \\
\hline b(blank) & 0 & tidak ada hubungan \\
\hline & 1 & mungkin ada hubungan \\
\hline & 3 & sedikit ada hubungan \\
\hline & 7 & sangat kuat hubungannya \\
\hline
\end{tabular}

\section{Penentuan sifat-sifat rekayasa teknis}

Yaitu menentukan rekayasa teknis atau jawaban langkah-langkah dari atribut pelanggan(pasien) untuk memenuhinya dengan pertimbangan sebagai berikut :

1. Normalized importance to customer $=$

$$
\frac{\text { Impor tance to customer }}{\text { Total Impor tance }}
$$

Priorities $=$

$\sum$ (Normalized to customer X Relationship Matrix Numerik)

\section{Benchmarking}

\section{Target}

Mempunyai Simbolnya adalah sebagai berikut :

$$
\begin{aligned}
\uparrow & =\text { lebih baik maximum (meningkat) } \\
\downarrow & =\text { lebih baik minimum } \\
& \text { (mengurangi) } \\
\bigcirc= & \text { target value }
\end{aligned}
$$




\section{METODOLOGI PENELITIAN}

\section{Data yang Diperlukan}

\section{* Data Kualitatif}

Dalam melakukan pengumpulan data kualitatif dilakukan dengan cara melakukan interview ke beberapa Rumah Sakit yang berada di Malang untuk mengetahui dan mengenal lebih lanjut keinginan dan kebutuhan pasien akan jasa pelayanan dan fasilitas yang diberikan Rumah Sakit secara umum. Dalam hal ini adalah mengidentifikasi kebutuhan pasien atau mengidentifikasi atribut apa yang dibutuhkan oleh pasien. Semua data yang dikumpulkan masih berupa data mentah yang biasanya disebut customer phrase. Voice of Customer Table (VOCT). (True Customer Need) (SQC, Function, Reliability, Target Value).

\section{* Data Kuantitatif}

1. Importance to customer yaitu tingkat kepentingan atribut

2. Customer satisfaction performance yaitu nilai seberapa baik jasa Rumah Sakit Saiful Anwar dalam memenuhi kebutuhan dan keinginan pasien

3. Competitive satisfaction performance yaitu seberapa baik jasa Rumah Sakit saingan dalam memenuhi kebutuhan dan keinginan pasien.

4. Data untuk menentukan sales point sehubungan dengan pemenuhan atribut.

\section{Kerangka Penyelesaian Masalah}

Dalam penerapan QFD yaitu pada pencarian spesifikasi kebutuhan (voice of customer), dan rekayasa teknis untuk kebutuhan/keinginan customer pada jasa pelayanan dan fasilitas Rumah Sakit mengikuti tahap-tahap penelitian yang secara umum implementasi Quality Function Deployment terdiri dari tiga fase, yaitu fase 0 tahap perencanaan dan persiapan; fase 1 tahap mengumpulkan suara pelanggan; fase 2 tahap membangun rumah kualitas; dan fase 3 analisa dan interpretasi hasil.

Fase-fase tersebut merupakan langkah-langkah penyusunan Rumah Kualitas yang dikelompokkan menjadi 5 langkah, yaitu : tahap identifikasi (I), tahap pengumpulan data (II), tahap pengolahan data (III), tahap penyusunan Rumah Kualitas (IV), tahap interpretasi hasil analisa serta pengambilan kesimpulan dan saran (V).

\section{HASIL DAN PEMBAHASAN}

\section{Uji Validitas}

Nilai korelasi korelasi (r) untuk ke empat jenis data seperti pada tabel sebagai berikut :

Tabel 3

Nilai r Data Importance to Customer dan Customer Satisfaction Performance

\begin{tabular}{|c|c|c|}
\hline \multirow{2}{*}{ Pernyataan } & \multicolumn{2}{|c|}{ Nilai r } \\
\cline { 2 - 3 } & $\begin{array}{c}\text { Importance to } \\
\text { Customer }\end{array}$ & $\begin{array}{c}\text { Customer } \\
\text { Satisfaction } \\
\text { Performance }\end{array}$ \\
\hline Pernyataan 1 & 0.9 & 0.7 \\
\hline Pernyataan 2 & 0.8 & $0.6+$ \\
\hline Pernyataan 3 & 0.7 & 0.6 \\
\hline Pernyataan 4 & 0.6 & 0.9 \\
\hline Pernyataan 5 & 0.7 & 0.8 \\
\hline Pernyataan 6 & 0.9 & 0.6 \\
\hline Pernyataan 7 & 0.7 & 0.8 \\
\hline Pernyataan 8 & 0.8 & 0.8 \\
\hline
\end{tabular}


Tabel 4

Nilai $r$ data competitive satisfaction performance RSUD dan sales point

\begin{tabular}{|c|c|c|c|c|}
\hline \multirow{2}{*}{ Pernyataan } & \multicolumn{4}{|c|}{ Nilai r } \\
\cline { 2 - 5 } & Jember & Madiun & Probolinggo & Saler Point \\
\hline Pernyataan 1 & 0.9 & 0.8 & 0.8 & 0.7 \\
\hline Pernyataan 2 & 0.9 & 0.9 & 0.7 & 0.8 \\
\hline Pernyataan 3 & 0.9 & 0.9 & 0.8 & 0.7 \\
\hline Pernyataan 4 & 0.8 & 0.9 & 0.9 & 0.8 \\
\hline Pernyataan 5 & 0.7 & 0.8 & 0.8 & 0.9 \\
\hline Pernyataan 6 & 0.8 & 0.7 & 0.7 & 0.8 \\
\hline Pernyataan 7 & 0.8 & 0.7 & 0.9 & 0.7 \\
\hline Pernyataan 8 & 0.8 & 0.9 & 0.8 & 0.7 \\
\hline
\end{tabular}

\section{Uji reliabilitas}

Perhitungan dengan menggunakan empat jenis data seperti pada tabel sebagai berikut :

rumus koefisien variansi (Rtt) untuk ke

Tabel 5

Nilai Rtt Data Importance to Customer dan Customer Satisfaction Performance

\begin{tabular}{|c|c|c|}
\hline Pernyataan & Importance to Customer & Customer Satisfaction Performance \\
\hline Pernyataan 1 & 0.92 & 0.90 \\
\hline Pernyataan 2 & 0.86 & 0.88 \\
\hline Pernyataan 3 & 0.75 & 0.86 \\
\hline Pernyataan 4 & 0.75 & 0.85 \\
\hline Pernyataan 5 & 0.84 & 0.85 \\
\hline Pernyataan 6 & 0.7 & 0.84 \\
\hline Pernyataan 7 & 0.95 & 0.83 \\
\hline Pernyataan 8 & 0.8 & 0.80 \\
\hline
\end{tabular}

Tabel 6

Nilai Rtt data competitive satisfaction performance RSUD dan Sales Point

\begin{tabular}{|c|c|c|c|c|}
\hline \multirow{2}{*}{ Pernyataan } & \multicolumn{4}{|c|}{ Nilai Rtt } \\
\cline { 2 - 5 } & Jember & Madiun & Probolinggo & Sales Point \\
\hline Pernyataan 1 & 0.89 & 0.88 & 0.87 & 0.96 \\
\hline Pernyataan 2 & 0.89 & 0.89 & 0.88 & 0.98 \\
\hline Pernyataan 3 & 0.76 & 0.88 & 0.88 & 0.97 \\
\hline Pernyataan 4 & 0.87 & 0.89 & 0.86 & 0.96 \\
\hline Pernyataan 5 & 0.88 & 0.91 & 0.9 & 0.93 \\
\hline Pernyataan 6 & 0.83 & 0.83 & 0.83 & 0.96 \\
\hline Pernyataan 7 & 0.86 & 0.869 & 0.84 & 0.98 \\
\hline Pernyataan 8 & 0.86 & 0.89 & 0.89 & 0.98 \\
\hline
\end{tabular}


Planning Matrix

Tabel 7

Importance to customer

\begin{tabular}{|l|c|c|}
\hline \multicolumn{1}{|c|}{ Atribut } & $\begin{array}{c}\text { Weighted } \\
\text { Importance } \\
\text { To customer }\end{array}$ & $\begin{array}{c}\text { Importance } \\
\text { to customer }\end{array}$ \\
\hline Biaya & 618 & 6.87 \\
\hline Kemudahan Birokrasi & 535 & 5.94 \\
\hline Kenyamanan & 454 & 5.04 \\
\hline Kepuasan & 397 & 4.41 \\
\hline Keamanan & 240 & 2.67 \\
\hline Kekeluargaan & 330 & 3.67 \\
\hline Keakuratan & 666 & 7.4 \\
\hline Waktu pelayanan & 285 & 3.17 \\
\hline
\end{tabular}

Tabel 8

Customer Satisfaction Performance

\begin{tabular}{|l|c|c|}
\hline \multicolumn{1}{|c|}{ Atribut } & $\begin{array}{c}\text { Weighted } \\
\text { Customer } \\
\text { Satisfaction } \\
\text { Performance }\end{array}$ & $\begin{array}{c}\text { Customer } \\
\text { Satisfaction } \\
\text { performance }\end{array}$ \\
\hline Biaya & 310 & 3.44 \\
\hline Kemudahan Birokrasi & 250 & 2.78 \\
\hline Kenyamanan & 277 & 3.08 \\
\hline Kepuasan & 259 & 2.97 \\
\hline Keamanan & 306 & 3.4 \\
\hline Kekeluargaan & 282 & 3.13 \\
\hline Keakuratan & 288 & 3.2 \\
\hline Waktu pelayanan & 250 & 2.78 \\
\hline
\end{tabular}

Tabel 9

Competitive Satisfaction Performance RSUD

\begin{tabular}{|l|c|c|c|c|c|c|}
\hline \multicolumn{1}{|c|}{ Atribut } & \multicolumn{2}{c|}{ Weighted Competitive Satisfaction Performance } & \multicolumn{2}{c|}{ Competitive Satisfaction Performance } \\
\hline & Jember & Madiun & Probolinggo & Jember & Madiun & Probolinggo \\
\hline Biaya & 312 & 300 & 309 & 3.47 & 3.33 & 3.43 \\
\hline Kemudahan Birokrasi & 304 & 307 & 278 & 3.38 & 3.41 & 3.12 \\
\hline Kenyamanan & 320 & 301 & 272 & 3.56 & 3.34 & 3.06 \\
\hline Kepuasan & 321 & 312 & 280 & 3.57 & 3.47 & 3.11 \\
\hline Keamanan & 282 & 299 & 300 & 3.13 & 3.32 & 3.33 \\
\hline Kekeluargaan & 312 & 319 & 302 & 3.47 & 3.54 & 3.36 \\
\hline Keakuratan & 296 & 284 & 295 & 3.29 & 3.16 & 3.28 \\
\hline Waktu pelayanan & 299 & 284 & 275 & 3.32 & 3.16 & 3.06 \\
\hline
\end{tabular}

\section{Sales point}

Tabel 10

Nilai Sales Point

\begin{tabular}{|c|c|}
\hline Atribut & Nilai sales Point \\
\hline Biaya & 1.2 \\
\hline Kemudahan Birokrasi & 1.5 \\
\hline Kenyamanan & 1.5 \\
\hline Kepuasan & 1.2 \\
\hline Keamanan & 1.2 \\
\hline Kekeluargaan & 1.5 \\
\hline Keakuratan & 1.5 \\
\hline Waktu pelayanan & 1.5 \\
\hline
\end{tabular}

\section{Goal}

Penentuan nilai goal ini adalah sebagai berikut :
- Pertimbangan nilai importance to customer, memberi bobot tinggi pada yang nilainya tinggi pula.

Tabel 11

Nilai Goal dari Importance to Customer

\begin{tabular}{|l|c|c|}
\hline \multicolumn{1}{|c|}{ Atribut } & $\begin{array}{c}\text { Weighted } \\
\text { Importance } \\
\text { To customer }\end{array}$ & Nilai Goal \\
\hline Biaya & 618 & 7 \\
\hline Kemudahan Birokrasi & 535 & 6 \\
\hline Kenyamanan & 454 & 5 \\
\hline Kepuasan & 397 & 4 \\
\hline Keamanan & 240 & 1 \\
\hline Kekeluargaan & 330 & 3 \\
\hline Keakuratan & 666 & 8 \\
\hline Waktu pelayanan & 285 & 2 \\
\hline
\end{tabular}


- Perbandingan nilai customer satisfaction dan competitive satisfaction performance. Karena rata-rata pesaing mempunyai nilai (performance) yang lebih baik maka kebijaksanaan penekanannya terletak pada nilai atribut yang mempunyai nilai paling sedikit, seperti pada tabel berikut :

Tabel 12

Nilai Goal dari Perbandingan nilai customer satisfaction dan competitive satisfaction Performance

\begin{tabular}{|l|c|}
\hline \multicolumn{1}{|c|}{ Atribut } & Nilai Goal \\
\hline Biaya & 3 \\
\hline Kemudahan Birokrasi & 8 \\
\hline Kenyamanan & 6 \\
\hline Kepuasan & 7 \\
\hline Keamanan & 3 \\
\hline Kekeluargaan & 5 \\
\hline Keakuratan & 4 \\
\hline Waktu pelayanan & 8 \\
\hline
\end{tabular}

- Pertimbangan nilai sales point

Tabel 13

Nilai Goal dari nilai sales point

\begin{tabular}{|l|c|c|c|}
\hline Atribut & \multicolumn{3}{|c|}{ Nilai Goal } \\
\hline & Tinggi & Rendah & Rata-rata \\
\hline Biaya & 4 & 2 & 4 \\
\hline Kemudahan Birokrasi & 7 & 3 & 6 \\
\hline Kenyamanan & 7 & 6 & 6 \\
\hline Kepuasan & 5 & 5 & 5.25 \\
\hline Keamanan & 3 & 7 & 3.5 \\
\hline Kekeluargaan & 6 & 8 & 5.5 \\
\hline Keakuratan & 8 & 5 & 6.25 \\
\hline Waktu pelayanan & 7 & 4 & 5.25 \\
\hline
\end{tabular}

\section{Improvement Ratio}

Dari perhitungan pada lampiran $\mathrm{C}$ didapatkan nilai improvement Ratio sebagai berikut :
Tabel 14

Nilai Improvement Ratio

\begin{tabular}{|l|c|}
\hline \multicolumn{1}{|c|}{ Atribut } & Improvement Ratio \\
\hline Biaya & 1.163 \\
\hline Kemudahan birokrasi & 2.158 \\
\hline Kenyamanan & 1.948 \\
\hline Kepuasan & 1.768 \\
\hline Keamanan & 1.029 \\
\hline Kekeluargaan & 1.757 \\
\hline Keakuratan & 1.953 \\
\hline Waktu pelayanan & 1.888 \\
\hline
\end{tabular}

\section{Raw Weight}

Tabel 15

Nilai Raw weight

\begin{tabular}{|l|l|}
\hline \multicolumn{1}{|c|}{ Atribut } & Raw Weight \\
\hline Biaya & 862.33 \\
\hline Kemudahan birokrasi & 1732 \\
\hline Kenyamanan & 1326.6 \\
\hline Kepuasan & 842.12 \\
\hline Keamanan & 296.47 \\
\hline Kekeluargaan & 869.81 \\
\hline Keakuratan & 1951.2 \\
\hline Waktu pelayanan & 807.33 \\
\hline
\end{tabular}

Normalized Raw weight dan

\section{Cummulative Normalized Raw Weight}

Dari perhitungan pada lampiran $\mathrm{C}$ didapatkan nilai raw weight seperti pada tabel berikut :

\section{Tabel 16}

Nilai Normalized Raw weight \& Cummulative Normalized Raw Weight

\begin{tabular}{|l|c|c|}
\hline \multicolumn{1}{|c|}{ Atribut } & $\begin{array}{c}\text { Normalize } \\
\text { d Raw } \\
\text { weight }\end{array}$ & $\begin{array}{c}\text { Cummulative } \\
\text { Normalized } \\
\text { Raw Weight }\end{array}$ \\
\hline Biaya & 0.099 & 0.099 \\
\hline Kemudahan Birokrasi & 0.199 & 0.299 \\
\hline Kenyamanan & 0.153 & 0.451 \\
\hline Kepuasan & 0.097 & 0.548 \\
\hline Keamanan & 0.0341 & 0.582 \\
\hline Kekeluargaan & 0.10 & 0.682 \\
\hline Keakuratan & 0.225 & 0.907 \\
\hline Waktu pelayanan & 0.093 & 1 \\
\hline
\end{tabular}




\author{
Memunculkan Substitute Quality \\ Characteristics (SQC) / Respon Teknis \\ Melakukan tahap-tahap sebagai \\ berikut yang keseluruhan langkah \\ langkahnya dibantu oleh Dokter, paramedis \\ dan pihak anministrasi yang ada di rumah \\ sakit : \\ 1. Menentukan Matriks hubungan \\ (Relationship Matrix) antara SQC \\ dengan Customer needs \\ 2. Menentukan Korelasi Teknis (Technical \\ Correlations) \\ 3. Menentukan Priorities \\ 4. Benchmarking \\ 5. Penentuan Target
}

\section{KESIMPULAN}

Dari analisa dapat dibuat perancangan sistem pelayanan dalam bentuk Rumah Kualitas (House of Quality) sebagai berikut :

Dari planning matrix (matriks perencanaan) dapat disimpulkan bahwa untuk meningkatkan pelayanan, langkah awal yaitu menitik beratkan pada atribut setelah melihat dari berbagai aspek pertimbangan yang seperti terlihat pada gambar planning matrix yaitu Importance to Custosmer, Customer Satisfaction Performance, Competitive Satisfaction Performance, Sales point dan Goal, adalah sebagai berikut :
1. Keakuratan
2. Kemudahan birokrasi
3. Kenyamanan
4. Kekeluargaan
5. Biaya
6. Kepuasan
7. Waktu pelayanan
8. Keamanan

\section{DAFTAR PUSTAKA}

Cohen, Lou, 1995, Quality Function Deployment How To Make QFD Work for You, by Eddison Wesley Publishing Company.

Guinta, Lawrence \&Praizler, Nancy, 1993, The $Q F D$ Book, by AMACOM (American Management Association) Jablonski, Joseph, 1992, Implementing $T Q M$, Second edition, by Pfeiffer \& Company 8517 Production.

Tjiptono, Fandy, 1997, Total Quality Service, Edisi pertama, Penerbit Andi, Yogyakarta.

Kotler, Philip, 1997, Analisa, Planning,

Implementation, and Control, Ninth Edition, by A Simon \& Schuter Company.

Rao, Ashok, 1996, TQM Across Functional

Perspective, by John Wiley \& Sons. 